\title{
PERANCANGAN APLIKASI PROMOSI UNIVERSITAS ISLAM INDRAGIRI BERBASI MULTIMEDIA INTERAKTIF
}

\author{
Bayu Rianto ${ }^{1}$ dan Indrawan Alsa ${ }^{2}$ \\ ${ }_{1,2}$ Sistem Informasi, Fakultas Teknik dan Ilmu Komputer, Universitas Islam Indragiri, Tembilahan \\ Email: rianto.bayu91@gmail.com (korespondensi)
}

\begin{abstract}
Islamic University of Indragiri or commonly abbreviated as UNISI is a public university located in Indragiri Hilir, Riau. The local government was the initiator of UNISI to develop the quality of human resources. Islamic University of Indragiri has a mission to encourage, develop the region so that it remains an economic activity based on a people's economy in Indragiri Hilir Regency. In terms of the conventional promotion of the Islamic University of Indragiri (UNISI), namely by distributing brochures, banners and goes school to school in Indragiri Hilir using these brochures. Based on this condition, it turns out that the promotional activities of the Islamic University of Indragiri are still not attractive and do not attract the public's interest in getting to know the Islamic University of Indragiri because the promotion system is just like that and also the large expenditure of funds for making brochures and banners. To solve this problem, it is necessary to have an interactive multimedia-based system for promotional activities in the form of promotional media and interactive multimedia-based information and its supporters. This multimedia will be able to contain information accompanied by pictures. In this media will also display a profile and a complete explanation of the Islamic University Indragiri. This media is packaged in the form of an application and makes it easier for the public to access it
\end{abstract}

Keywords: design, interactive multimedia-based promotion system.

\begin{abstract}
Abstrak
Universitas Islam Indragiri atau biasa disingkat dengan nama UNISI adalah sebuah perguruan tinggi negeri yang terletak di Indragiri hilir, Riau. Pemerintah daerah merupakan pencetus dari UNISI untuk mengembangkan kualitas sumber daya manusia. Universitas Islam Indragiri mempunyai misi untuk mendorong, menggembangkan pembangunan daerah agar tetap menjadi kegiatan ekonomi yang berbasis ekonomi kerakyatan di Kabupaten Indragiri Hilir. Dalam hal promosi Universitas Islam Indragiri (UNISI) masih secara konvensional yaitu melalui penyebaran brosur, spanduk dan memberikan sosialisasi ke sekolah-sekolah yang ada di Indragiri Hilir menggunakan brosur-brosur tersebut. Melihat kondisi ini ternyata kegiatan promosi Universitas Islam Indragiri masih bersifat kurang menarik dan kurangnya minat masyarakat untuk mengenal Universitas Islam Indragiri di karenakan sistim promosi yang begitu-gitu saja dan juga terjadinya pengeluaran dana yang banyak untuk pembuatan brosur dan spanduk. Untuk mengatasi permasalahan tersebut perlu adanya sistem yang berbasis multimedia interaktif untuk kegiatan promosi berupa media promosi dan informasi yang berbasis multimedia interaktif beserta pendukungnya. Multimedia ini akan mampu memuat informasi yang di sertai gambar. Di dalam media ini juga akan menampilkan profil dan penjelasan lengkap tentang Universitas Islam Indragiri. Media ini nantinya akan dikemas dalam bentuk aplikasi android yang memudahkan masyarakat untuk mengaksesnya
\end{abstract}

Kata kunci: perancangan, sistem promosi, berbasis multimedia interaktif.

\section{PENDAhUlUaN}

Multimedia merupakan salah satu dari produk teknologi informasi yang ada saat ini. Lahirnya teknologi multimedia merupakan hasil dari perpaduan kemajuan teknologi elektronik, teknik komputer dan perangkat lunaknya (software). Dengan 
didukung oleh aplikasi multimedia inilah perguruan tinggi dapat menjalani promosi lebih lancer dan menarik.

Universitas Islam Indragiri atau biasa disingkat dengan nama UNISI adalah sebuah perguruan tinggi negeri yang terletak di Indragiri hilir, Riau. Pemerintah daerah merupakan pencetus dari UNISI untuk mengembangkan kualitas sumber daya manusia. Universitas Islam Indragiri mempunyai misi untuk mendorong, menggembangkan pembangunan daerah agar tetap menjadi kegiatan ekonomi yang berbasis ekonomi kerakyatan di Kabupaten Indragiri Hilir Dalam hal promosi Universitas Islam Indragiri (UNISI) masih secara konvensional yaitu melalui penyebaran brosur, spanduk dan memberikan sosialisai kesekolah-sekolah yang ada di Indragiri Hilir mengunkan brosur-brosur tersebut. Melihat kondisi ini ternyata kegiatan promosi Universitas Islam Indragiri masih berifat kurang menarik dan kurangnya minat masyarkat untuk mengenal Universitas Islam Indragiri di karenakan sistim promosi yang begitu-gitu saja dan juga terjadinya pengeluaran dana yang banyak untuk pembuatan brosur dan spanduk.

Dengan adanya media ini diharapkan kegiatan promosi dapat lebih maksimal dan menarik. Yang bertujuan adalah untuk membantu dalam upaya memberikan informasi tentang Universitas islam indragiri dan mempromosikan melalui media yang menarik dan informatif.

Multimedia ini akan mampu memuat informasi yang di sertai gambar.di dalam media ini juga akan menampilkan profil dan penjelasan lengkap tentang Universitas Islam Indragiri. Media ini nantinya akan dikemas dalam bentuk aplikasi androit yang memudahkan mengaksesnya.

\section{TINJAUAN PUSTAKA}

\subsection{Sistem}

Sistem adalah suatu jaringan kerja dari prosedur-prosedur yang saling berhubungan, berkumpul bersama-sama untuk melakukan kegiatan atau untuk melakukan sasaran yang tertentu. Pendekatan sistem yang merupakan jaringan kerja dari prosedur lebih menekankan urutan-urutan operasi di dalam sistem Hutahaean (2015:2-3).

\subsection{Informasi}

Informasi adalah data yang diolah menjadi bentuk yang lebih berguna dan lebih berarti bagi penerimanya. Sumber informasi adalah data. Data kenyataan yang menggambarkan suatu kejadian-kejadian dan kesatuan nyata. Kejadian- kejadian adalah kejadian yang terjadi pada saat tertentu (Hutahaean, 2015:10).

\subsection{MULTIMEDIA INTERAKTIF}

Multimedia interaktif adalah media yang menggabungkan teks, grafik, video, animasi, dan suara. Guna menyampaikan suatu pesan dan informasi, melalui media elektronik seperti komputer dan perangkat elektronik lainnya(Nurcahyo 2019.).

\subsection{ANDROIT}

Menurut Safaat (2012) Android adalah sistem operasi menggunakan Linux yang dirancang untuk perangkat seluler seperti telepon pintar (smartphone) dan komputer tablet. Android awalnya dikembangkan oleh Android, Inc.. dengan dukungan finansial dari Google yang kemudian membelinya pada tahun 2005 .

\subsection{Konsep Pemodelan UML}

Unifield Modeling Language (UML) merupakan bahasa visual untuk pemodelan dan komunikasi mengenai sebuah sistem dengan menggunakan diagram dan teks-teks pendukung.UML hanya berfungsi untuk melakukan pemodelan.Jadi penggunaan UML tidak terbatas pada metodologi tertentu, meskipun pada kenyataannya UML paling banyak digunakan pada metodologi berorientasi objek.

1. UseCaseDiagram

Use Case Use case merupakan pemodelan untuk kelakuan (behavior) sistem informasi yang akan dibuat. Use case mendeskripsikan sebuah interaksi antara satu atau lebih aktor dengan sistem informasi yang akan dibuat. Secara kasar, Use case digunakan untuk mengetahui fungsi apa saja yang ada dalam sebuah sistem informasi dan siapa saja yang berhak menggunakan fungsi-fungsi itu (Rosa dan Shalahuddin, 2013).

Tipe relasi yang mungkin terjadi pada use casediagram:

a $<$ include $>>$, yaitu kelakuan yang harus terpenuhi

b agar sebuah event dapat terjadi, dimana pada kondisi ini sebuah usecase adalah bagian dari usecase lainnya.

c $<<$ extends $>>$, kelakuan yang hanya berjalan di bawah kondisi 
tertentu seperti menggerakkan peringatan.

d $<<$ communicates $>>$, merupakan pilihan selama asosiasi hanya tipe relationship yang dibolehkan antara actor danuse case.

\section{METODOLOGI PENELITIAN}

Metode penelitian merupakan cara atau teknik yang digunakan dalam rancangan bagun sistem informasi ini. Adapun Metode yang diakukandalam penelitian ini adalah sebagai berikut:

\subsection{Metode Analisa Data}

Analisa dan perancangan sistem informasi penjualan pada Showroom Master ini dilakukan dengan menggunakan metode Analisa PIECES.

a) Performance (kinerja)

Analisa kinerja adalah kemampuan dalam menyelesaikan tugas dengan cepat sehingga dapat segera tercapai,analisa kinerja dapat dilakukan dengan mengukur jumlah produksi (troughtout) dan waktu tanggap (responce time), dari sistem promosi yang sedang digunakan diperguruan tinggi UNISI sistem yang sedang berjalan saat ini permasalahan yang dihadapi adalah sistim yang kurang menarik di karenakan hanya mengunakan penyebaran brosur dan pemasangan spanduk.

b) Information (informasi)

Informasi merupakan hal yang penting untuk proses pengambilan keputusan, oleh sebab itu diharapkan adanya informasi yang akurat, tepat waktu dan relevan.sehingga informasi ini nantinya dapat berguna oleh pihak yang membutuhkan. Berdasarkan analisa informasi pada tempat studi kasus kelemahan yang ada pada sistem yang berjalan adalah Kuruangnya penyampaian secara lengkap tentang UNISI yang dilakukan pihak Promosi ke masyarakat.

c) Economy (ekonomi)

Analisa ekonomi adalah penilaian sistem dalam pengurangan dan keuntungan yang akan didapatkan dari sistem yang akan dikembangkan .sistem ini akan memberikan penghematan. pemborosan pada sistem lama sangat kelihatan salah satunya yaitu pemborosan dalam pembuatan brosur dan spanduk. Brosur dan spanduk tersebut digunakan untuk memberi informasi tentang UNISI dalam jangka waktu satu tahun,sehingga jika untuk tahun berikutnya brosur dan spanduk dibuat kembali untuk membrikan informasi yang baru tentang perguruan tinggi tersebut yaitu UNISI. Sehingga UNISI mengeluarkan dana yang banyak setiap tahunnya untuk pembuatan brosur-brosur dan spanduk untuk promosi.

d) Control (pengendalian)

Analisa pengendalian sangatlah dibutuhkan. Hal ini untuk menghindari dan mendeteksi secara dini terhadap penyalahgunaan atau kesalahan system serta untuk meenjamin keamanan informasi. Berdasarkan analisis pengendalian system yang ada distudi kasus, sistem disana sangatlah kurang, ini terlihat banyaknya penumpukan berkas kesalahan saat masyarakat saat mendaftar dikarenakan masyarkat yang masih belum kurang mengerti dari cara masuk dan sistim kuliah yang ada tertera di spanduk ataupun browsur sehingga di bidang promosi harus menjelaskan berulang-ulang kemasyarakat. Dilihat dari system yang sedang berjalan distudi kasus saat ini, system masih kurang efisien karena saat ini, masih melakukan promosi secara manual sehingga membutuhkan waktu yang lama untuk menyebarkan informasi tersebut

e) Service (pelayanan)

Peningkatan pelayanan terhadap masyarakat merupakan tujuan utama pada kasus ini. Dari proses pelayanan dirasa cukup baik namun membutuhkan sosialisai yang lebih untuk mengajarkan cara mengunakan sistem ini.

\section{HASIL DAN PEMBAHASAN}

Tahap perancangan sistem informasi ini merupakan alat bantu untuk mendesain sistem baru yang akan dibuat, yang tujuannya adalah mengurangi kelemahankelemahan sistem.

\subsection{Perancangan Proses}

Dalam perancangan proses ini, ada beberapa rancangan yang akan dipaparkan. Berikut ini adalah rancangan sistem secara umum yang diusulkan.

a) Use Case diagram

Salah satu diagram penting yang digunakan untuk mengilustrasikan kebutuhan (requirements) dari sistem adalah use case (UC) diagram, yang menjelaskan secara visual konteks dari interaksi antara aktor dengan sistem. 
Setiap use case menyatakan spesifikasi perilaku (fungsionalitas) dari sistem yang sedang dijelaskan yang memang dibutuhkan oleh aktor untuk memenuhi tujuannya (Kurniawan, 2018).

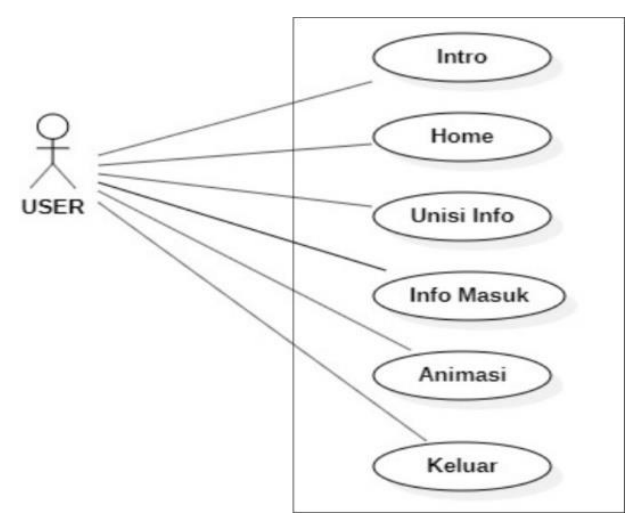

Gambar 1 Use case diagram

Gambar 1 di atas adalah usecase diagram aplikasi promosi perguran tinggi unisi yang dirancang Adapun aktor yang terlibat di dalam sistem dapat didefinisikan dengan satu aktor, yaitu user. Yang dimana peranan User ini adalah merupakan orang yang memakai aplikasi promosi perguruan tingg Unisi. User dapat melihat halaman utama dan memilih pilihan yang tersedia.

\subsection{Perancangan muka \\ Interface/Antar}

Perancangan Interface mengandung penjelasan tentang rancangan antar muka dari aplikasi promosi Universitas islam indragiri. yang dimana menjelaskan setiap rancangan Interface pada setiap menu dan menjelaskan pengunaan fungsi tombol pada aplikasi promosi Universitas Islam Indragiri. Untuk rancangan interface ini yang dimana akan dikemas dalam bentuk aplikasi androit maka bentuk dari aplikasi ini berbentuk horizontal.

Perancangan antar muka dapat dijelaskan satu persatu setiap menu dari intro sampai menu keluar.

a) Interface Halaman intro

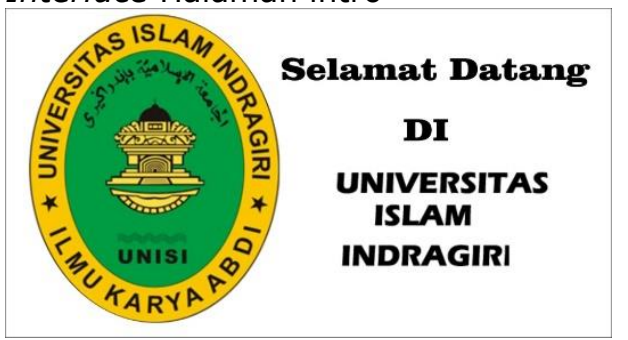

Gambar 2 Interface Halaman Intro Gambar 2 menjelaskan rancangan interface halaman intro yang dimana halaman intro menampilkan animasi pembuka yang di mana animasi ini berisikan animasi selamat datang di universitas islam indragiri.

b) Interface Halaman menu home

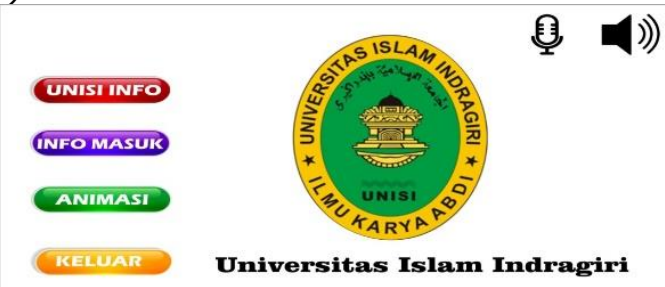

Gambar 3 Interface Halaman menu home Gambar 3 meupakan rancangan halaman menu home yang dimana manu home ini adalaha halaman utama dari aplikasi promosi universitas islam indragiri yang dimana halaman ini menentukan user untuk menuju halaman berikutnya. Dihalaman ini terdapat tombol-tombol untuk menuju kehalaman yang di inginkan.terapat halaman unisi info,info masuk,animasi,keluar dan juga terdapat tombol sound dan host yang membantu user.

c) Interface menu unisi info

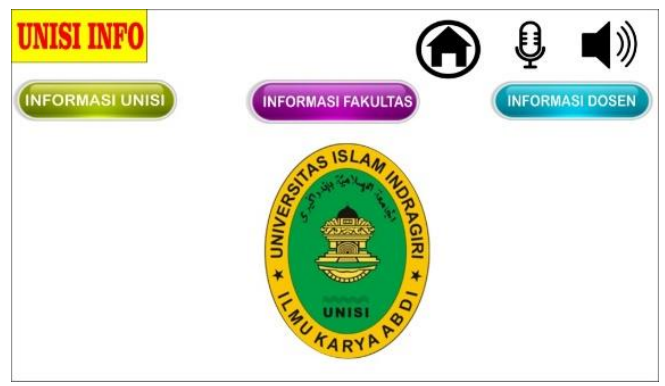

Gambar 4 merupakan rancangan untuk menu unisi info, di menu ini user dapat memilih informasi apa yang diinginkan yang dimana terdapat tombol sesuai keinginan user yaitu terdapat tombol informasi unisi,informasi fakultas,informasi dosen.

d) Interface menu Info masuk 


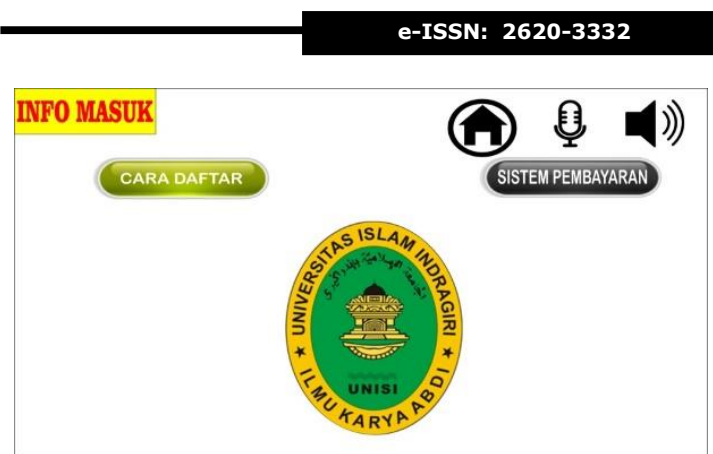

Gambar 5 Interface menu Info masuk Gambar 5 merupakan gambar untuk rancangan menu info masuk yang dimana pada menu ini adalah tempat untuk user mencari tau cara mendaftar dan melihat informasi pembayaran yang di mana terdapat tombolnya.

e) Interface menu animasi

\section{ANIMASI}
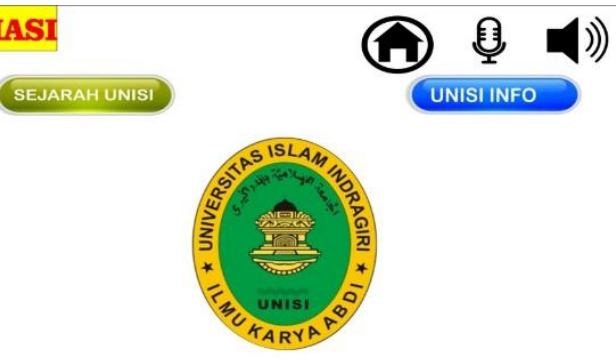

Gambar 6 Interface menu Animasi Gambar 6 merupakan rancangan untuk menu animasi yang dimana terdapat dua tombol yang berisikan konten animasi yang diiginkan oleh user.

\section{KESIMPULAN DAN SARAN}

UNISI adalah sebuah perguruan tinggi negeri yang terletak di Indragiri hilir, Riau. Pemerintah daerah merupakan pencetus dari UNISI untuk mengembangkan kualitas sumber daya manusia. Universitas Islam Indragiri mempunyai misi untuk mendorong, menggembangkan pembangunan daerah agar tetap menjadi kegiatan ekonomi yang berbasis ekonomi kerakyatan di Kabupaten Indragiri Hilir.Dengan dibuatnya media promosi dan informasi yang berbasis multimedia interaktif untuk promosi perguran tinggi universitas islam indragiri maka kegiatan promosi akan menjadi lebih informatif dan mampu mendukung kegiatan promosi menjadi lebih menarik untuk perhatian masyarakat terhadap perguran tinggi Dalam media ini juga dilengkapi media pendukung berupa media promosi animasi. animasi ini akan berisikan informasi singkat dari sejarah terbentuknya Universitas Islam Indragiri. dengan adanya media ini diharapkan kegiatan promosi dapat lebih maksimal dan menarik.

\section{DAFTAR PUSTAKA}

[1] Nurcahyo, Rudi, S Kom, Lin Mulyati, S Kom, S M K Mak, and Kelas Xii. n.d. "Desain Media Interaktif."

[2] Yunita, Firti, and Bayu Rianto. 2018. "Aplikasi Susun Gambar Pada TK Pertiwi Tembilahan." Journal of Technopreneurship and Information System (JTIS) 1 (1): 39-43. https://doi.org/10.36085/jtis.v1i2.29.

[3] Hutahaean, J. (2014). Konsep Sistem Informasi. Yogyakarta: Deepublish.

[4] Mardison. (2017). Perancangan Sistem Informasi Pembelian E-Tiket Dengan Menggunakan Aplikasi Metode Data Grafik CV.Tranex Mandiri Kota Pariaman Yang Di Dukung Oleh Bahasa Pemerograman PHP dan Databese MySQL. Jurnal Teknologi. Vol 7, 2301-4474

[5] Iswandy, E. (2015). Sistem Penunjang Keputusan Untuk Menentukan Penerimaan Dana Santunan Sosial Anak Nagari Dan Penyalurannya Bagi Mahasiswa Dan Pelajar Kurang Mampu Di Kenegrian Barung-Barung Balantai Timur. Jurnal TEKNOIF. Vol 3, 2338-2724

[6] Mahaseptiviana, A., Tjandrarini, A.B., dan Sudarmaningtyas, P (2014) Analisis Dan Perancangan Sistem Informasi Penjualan Air Minum Pada Cv. Air Putih. JSIKA Vol 3 No. 2, ISSN: 2338-137X

[7] Safaat, Nazruddin. Pemrograman Aplikasi Mobile Smartphone dan Tablet $P C$ Berbasis Android. Informatika Bandung, Bandung

[8] H. Al Fatta, Analisis dan Perancangan Sistem Informasi. Yogyakarta: Andi, 2007

[9] Sunarti, (2016). Rancang Bangun Sistem Peminjaman pada koperasi Hortina Direktorat Jendral Hortikultura Jakarta. Indonesian Journal on Computer and Information Technology. Vol 1, 234-562

[10] Rosa dan Shalahudin, 2013. Rekayasa Perangkat Lunak Terstruktur dan Berorientasi Objek. Bandung: INFORMARTIKA. 